\title{
Pyrite Biooxidation by Acidophilic Archaea AcidiplasmaSp. MBA-1 Under Varied Conditions
}

\section{Aleksandr Bulaev}

Winogradsky Institute of Microbiology, Research Center of Biotechnology of the Russian Academy of Sciences. 33, bld. 2 Leninsky Ave., Moscow 119071,Russia

\section{ORCID}

Aleksandr Bulaev; 0000-0001-7914-9817

Corresponding Author:

Aleksandr Bulaev; email:

bulaev.inmi@yandex.ru

Dates

Published 13 January 2022

Publishing services provided by Knowledge E

(c) Aleksandr Bulaev. This article is distributed under the terms of the Creative Commons

Attribution License, which permits unrestricted use and redistribution provided that the original author and source are credited.

Selection and Peer-review under the responsibility of the 8 th Scientific and Practical Conference Conference Committee.
G OPEN ACCESS
Abstract. The goal of this research was to study pyrite $\left(\mathrm{FeS}_{2}\right)$ bioleaching by a strain of the genus Acidiplasma under different conditions (temperature, $\mathrm{pH}$ ) to evaluate the potential role of Acidiplasma representatives in biooxidation of this sulfide mineral. To compare the role of Acidiplasma archaea in pyrite biooxidation with other acidophilic microorganisms, the experiments were also performed with representatives of othergroups of microorganisms predominant in biohydrometallurgical processes.Pure and mixed cultures of moderately thermophilic acidophilic microorganisms, including strains Acidithiobacillus caldus MBC-1, Sulfobacillusthermosulfidooxidans VKMV $1269^{T}$ and Acidiplasmasp. MBA-1, were used. The experiments were carried out in flasks with $100 \mathrm{~mL}$ of mineral nutrient medium supplemented with $0.02 \%$ yeast extract and $1 \mathrm{~g}$ of pyrite on a rotary shaker for 20 days. Bioleaching was performed at 45,55 , and $60^{\circ} \mathrm{C}$. The results demonstrated that the representatives of the genus Acidiplasmaprovided a comparatively higher rate of pyrite bioleaching at high temperatures (55 and $60^{\circ} \mathrm{C}$ ) and low $\mathrm{pH}$ of the medium (1.0). Thus, according to the results, strains of the genus Acidiplasma may provide a high rate of pyrite bioleaching at low levels ofpH. Therefore, the results suggest that archaea of the genus Acidiplasma may be promising microorganisms to improve bioleaching processes with an increase in the operational temperature, which is usually maintained at $40-45^{\circ} \mathrm{C}$ in industrial scale reactors.

Keywords: biomining, bioleaching, acidophilic microorganisms, sulfide minerals, pyrite

\section{Introduction}

Biomining (biohydrometallurgy)is widely used for treatment of sulfide ores and concentrates. The principle upon which the biohydrometallurgical processes is based is oxidative disruption ofthe crystal lattice of sulfide minerals byvarious acidophilic ironand sulfur-oxidizing microorganisms [1].

Biohydrometallurgical technologiesmay be applied toextract different non-ferrous and noble metals (e.g., copper, nickel, zinc, gold,and uranium) from sulfide ores and concentrates[1,2]. The most important area of biohydrometallurgy application is processing of refractory gold-bearing sulfide concentrates [1, 2].Pyrite $\left(\mathrm{FeS}_{2}\right)$, the most widespread sulfide mineral, is often a component ofrefractory gold-bearing ores and concentrates 
$[2,3]$. Therefore, pyrite biooxidation is of great importance for the processing refractory gold-bearing concentrates.

Mechanisms of pyritebioleaching [3, 4] and the effect of different factors on its biooxidation,including temperature, Eh, and properties of oxidizing microorganisms, have been actively studied $[5,6]$.As during pyrite bioleaching, $\mathrm{Fe}^{3+}$ ion, which is produced during pyrite bioleaching by iron-oxidizing microorganism, is the main oxidizing agent, iron-oxidizers play a key role in its disruption[3, 4, 5]. For example, it was show that iron-oxidizing bacteria Leptospirillum and Sulfobacillus played the most important role in pyrite biooxidation by mixed cultures of iron- and sulfur-oxidizing microorganisms [ 5 , 6, 7].

It should be noted that improvementofbiohydrometallurgical technologies may be based on the study of the microbe-mineral interactions and the effect of different factors on bioleaching of various sulfide minerals. One of the main factors affecting biooxidation of sulfide concentrates is temperature. As sulfide mineral oxidation is accompanied by heat generation,reactors of biooxidation plants are equipped with cooling systems to maintain the required temperature, while bioleaching processes on an industrial scale are usually performed at high temperature $\left(40-45^{\circ} \mathrm{C}\right)$ [2]. As maintaining of the required temperature comprises a significant part of OPEX during biooxidation of sulfide concentrates, performing processes at elevated temperatures may provide the decrease in production cost [8].

As the temperature also affects the composition of microbial populations performing biooxidation, study of pyrite biooxidation by the microorganisms predominant at different temperatures may be of interest. In industrial bioleaching processes, thermotolerant and moderately thermophilic microorganisms including bacteriaLeptospirillum, Sulfobacillus spp., and Acidithiobacillus caldus as well as archaea of the genera Ferroplasma and Acidiplasma of the family Ferroplasmaceae are predominant [2, 9, 10]. Representatives of the genus Acidiplasma are moderate thermophiles oxidizing iron and sulfur, whichpredominate in microbial populations performing bioleaching of different sulfide concentrates $[9,10]$. These archaea have temperature optimum $45-55^{\circ} \mathrm{C}$ and are able to grow at temperatures up to $65^{\circ} \mathrm{C}$. Thus, they are more resistant to the hightemperatures than other microorganisms predominant in biohydrometallurgical processes [11]. Therefore, performing bioleaching at elevated temperatures using these microorganisms may be promising approach to improve biooxidation processes. Therefore, bioleaching of different sulfide minerals by Acidiplasma archaea should be studied in detail. 
The goal of the present work was to study pyrite bioleaching by the strain of the genus Acidiplasma underdifferent conditions (temperature, $\mathrm{pH}$ ) to evaluate potential role of the representatives of the genus in biooxidation of this sulfide mineral. To compare the role of Acidiplasma archaea in biooxidation of this sulfide mineral with other acidophilic microorganisms, the experiments were also performed with representatives of othergroups of microorganisms predominant in biohydrometallurgical processes (strains of A.caldusandS. thermosulfidooxidans).

\section{Materials and Methods}

Sulfide mineral pyrite $\left(\mathrm{FeS}_{2}\right.$ ) (Akchatau mine, Karagandaregion, Kazakhstan) milled to a particlesize of not more than $75 \mu \mathrm{m}$ was used in the study. Pure and mixed cultures of moderately thermophilic acidophilic microorganisms, including strains Acidithiobacillus caldus MBC-1, Sulfobacillus thermosulfidooxidans VKMV $1269^{T}$, and Acidiplasma sp. MBA-1 previously isolated from samples of ores and pulp of biooxidation reactors were the subjects of the study. Properties of the strains are shown in Table 1. All strains were inoculated in the medium in such a way that initial cells number of each strain was about $1 \times 10^{8}$ cells $/ \mathrm{mL}$. The bioleaching was carried out in $250 \mathrm{~mL}$ Erlenmeyer flask with $100 \mathrm{~mL}$ of mineral nutrient medium containing salts of nitrogen and phosphorus ( $(\mathrm{g} / \mathrm{L})$ $\left.\left(\mathrm{NH}_{4}\right)_{2} \mathrm{SO}_{4}-3.0 ; \mathrm{KCl}-0.20 ; \mathrm{MgSO}_{4} \times 7 \mathrm{H}_{2} \mathrm{O}-0.5 ; \mathrm{K}_{2} \mathrm{HPO}_{4}-0.5\right)$ and $1 \mathrm{~g}$ of pyrite on a rotary shaker $(200 \mathrm{rpm})$ for 20 days, the medium was supplemented with $0.02 \%$ yeast extract. Bioleaching experiments were performed at 45,55 , and $60^{\circ} \mathrm{C}$. In some variants, initial $\mathrm{pH}$ was 1.5 , while in other variants it was 1.0. The following combinations of the strains and conditions were used in the work: (1) mixed culture of $A$. caldus MBC-1, S. thermosulfidooxidans VKMV $1269^{T}$, and Acidiplasma sp. MBA-1, $45^{\circ} \mathrm{C}$, initial $\mathrm{pH} 1.5$; (2) pure culture $S$. thermosulfidooxidans VKMV $1269^{T}, 45^{\circ} \mathrm{C}$, initial $\mathrm{pH} 1.5$; (3) pure culture Acidiplasma sp. MBA-1, $45^{\circ} \mathrm{C}$, initial pH 1.5; (4) pure culture Acidiplasma sp. MBA-1, $55^{\circ} \mathrm{C}$, initial pH 1.0; (5) pure culture Acidiplasma sp. MBA-1, $55^{\circ} \mathrm{C}$, initial $\mathrm{pH} 1.5$; (6) pure culture Acidiplasma sp. MBA-1, $60^{\circ} \mathrm{C}$, initial pH 1.0; (7) pure culture Acidiplasma sp. MBA-1, $60^{\circ} \mathrm{C}$, initial $\mathrm{pH} 1.5$.

\section{Table 1:}

To estimate pyrite bioleaching under different conditions,parameters of the liquid phase reflecting activity of iron- and sulfur-oxidizing microorganisms $(\mathrm{pH}$, Eh, concentrations of $\mathrm{Fe}^{2+}$ and $\mathrm{Fe}^{3+}$ ions) were determined. The concentrations of $\mathrm{Fe}^{2+}$ and $\mathrm{Fe}^{3+}$ ions were determined spectrophotometrically (at $475 \mathrm{~nm}$ ) using the rhodanide method based 
TABLE 1: Properties of the strains.

\begin{tabular}{|c|c|c|c|c|c|}
\hline \multirow[t]{2}{*}{ Microorganism } & \multicolumn{2}{|c|}{ Oxidation } & \multirow{2}{*}{$\begin{array}{l}\text { Optimum } \\
\text { temperature } \\
\text { / upper limit, }{ }^{\circ} \mathrm{C}\end{array}$} & \multirow{2}{*}{$\begin{array}{l}\text { Optimum } \\
\mathrm{pH}\end{array}$} & \multirow[t]{2}{*}{ Reference } \\
\hline & $\mathrm{Fe}^{2+}$ & $\mathrm{S}^{0}$ & & & \\
\hline A. caldus MBC-1 & - & + & $45 / 53$ & 2.0 & [9] \\
\hline $\begin{array}{l}\text { S. thermosulfidooxidans } \\
\text { VKMV } 1269^{T}\end{array}$ & + & + & $45-48 / 60$ & 2.0 & [11] \\
\hline Acidiplasma sp. MBA-1 & + & + & $50-55 / 63$ & 1.0 & [9] \\
\hline
\end{tabular}

on formation of a purple coordination complex of ferric iron ions $\mathrm{Fe}^{3+}$ and rhodanide $\mathrm{SCN}^{--}[13]$.

To compare the rate of pyrite leaching under different conditions, it was evaluated by the total concentration of iron ions in the medium, calculating the fraction of iron that was released into the solutionafter 20 days of the biooxidation.

\section{Results}

The results of the experiments under different conditions are shown in Figures 1, 2, and 3.Figure 1 demonstrates changes in liquid phase parameter during biooxidation pyrite by different microorganisms at $45^{\circ} \mathrm{C}$, while in Figure 2 , the liquid phase parameters during pyrite bioleaching by the strainAcidiplasma sp. MBA-1 at 55 and $60^{\circ} \mathrm{C}$ are shown. It should be noted that conditions of the experiment with the mixed culture and pure cultures of the strains S. thermosulfidooxidans VKMV $1269^{T}$ andAcidiplasma sp. MBA-1 at $45^{\circ} \mathrm{C}$ corresponded to those in laboratory-scale reactors during the trials performed in the work [9]. This work demonstrated that at $45^{\circ} \mathrm{Cin}$ laboratory reactors, biooxidation of pyrite-arsenopyrite gold bearing concentrate was performed by mixed microbial population, which formed during long-term biooxidation process and included strains $A$. caldus,S. thermosulfidooxidans, andAcidiplasma. Therefore, the results of the present work made it possible to evaluate the potential role of the strains of mixed population formed in bioleach experiment in pyrite bioleaching during model experiment.

It was shown that pyrite bioleaching was the most active in the variant with mixed culture of three strains (Figure 1) that was determined by the liquid phase parameters. While the $\mathrm{pH}$ values were similar in all variants of the experiments (Figure $1 \mathrm{~A}$ ), Eh values and iron ions concentrations differed in the experiments with different cultures (Figures 1B, 1C, and 1D). It was shown that by the end of the experiment, Eh value as well as ferric iron ion concentration was the highest in the experiment with the mixed culture (Figures $1 \mathrm{~B}$ and $1 \mathrm{C}$ ). It should be noted that ferrous iron ion was not detected 
during the bioleaching (Figures 1D), which in turn demonstrated high iron-oxidizing activity of the culture. In the same time, in the experiment with the pure culture of $S$. thermosulfidooxidans VKMV $1269^{T}$, Eh values and ferric iron concentrations did not differ significantly from those observed in the experiment with the mixed culture up to $15^{\text {th }}$ day of the bioleaching (Figures $1 \mathrm{~B}$ and $1 \mathrm{C}$ ). After 15 days of the bioleaching, oxidizing activity of the strain S. thermosulfidooxidans VKMV $1269^{T}$ decreased that was reflected by the decrease in Eh and increase in ferrous iron concentration (Figures 1B and 1D). It may be explained by the fact that in the mixed cultures, autotrophic $A$. caldus may provide mixotrophic bacterium S. thermosulfidooxidans with organic exometabolites and maintain its activity during long-term experiments. In the same time, during pyrite bioleaching by the pure culture $S$. thermosulfidooxidans, its activity decreased by the end experiment due to thedepletion of added organic carbon source (yeast extract) [7].

In the variant with the pure culture of Acidiplasma sp. MBA-1, ferric iron ion concentrations were significantly lower than those in other variants (Figure 1C). In the same time, ferrous iron concentration (Figure 1D) were comparatively low and was detected only on the $15^{\text {th }}$ day, while Eh value insignificantly lower than in the variant with the mixed culture (Figure 1B). Pyrite bioleaching rate at $45^{\circ} \mathrm{C}$ was the highest in the experiment with the mixed culture, while it was insignificantly lower in the experiment with the strain S. thermosulfidooxidans VKMV $1269^{T}$ (Figure 3, bars 1 and 2). In the experiment with Acidiplasma sp. MBA-1, leaching rate was comparatively low (Figure 3, bar 3).

Thus, it was shown that a $45^{\circ} \mathrm{C}$ strain S. thermosulfidooxidans VKMV $1269^{T}$ played the main role in pyrite bioleaching since in the experiment with its pure culture leaching rate was almost as high as in the experiment with the mixed culture, while the strain Acidiplasma sp. MBA-1 leached pyrite less actively.

Figure 2 demonstrated results of pyrite bioleaching by the strain Acidiplasma sp. MBA- 1 at high temperatures $\left(55\right.$ and $60^{\circ} \mathrm{C}$ ) and different $\mathrm{pH}$ values(1.0 and 1.5).

It was shown that $\mathrm{pH}$ values changed insignificantly (Figure $2 \mathrm{~A}$ ) during the bioleaching. The Eh values (Figure $2 \mathrm{~B}$ ) were lower than those at $45^{\circ} \mathrm{C}$, while ferrous iron concentrations were higher than in the experiment at $45^{\circ} \mathrm{C}$ (Figures 1D and 2D). Therefore, it may be assumed that at high temperatures iron oxidation activity was inhibited despite $55^{\circ} \mathrm{C}$ corresponded to the optimum temperature of the strain. In the same time, ferrous iron concentrations at higher temperatures might be higher due to the increase in the rate of chemical reactions of ferric iron ions with pyrite that in turn led to the accumulation of ferrous iron ions in the medium. It should be noted that at both temperatures, ferric iron concentrations in the medium (Figure $2 \mathrm{C}$ ) were lower at $\mathrm{pH} 1.5$ in comparison to 

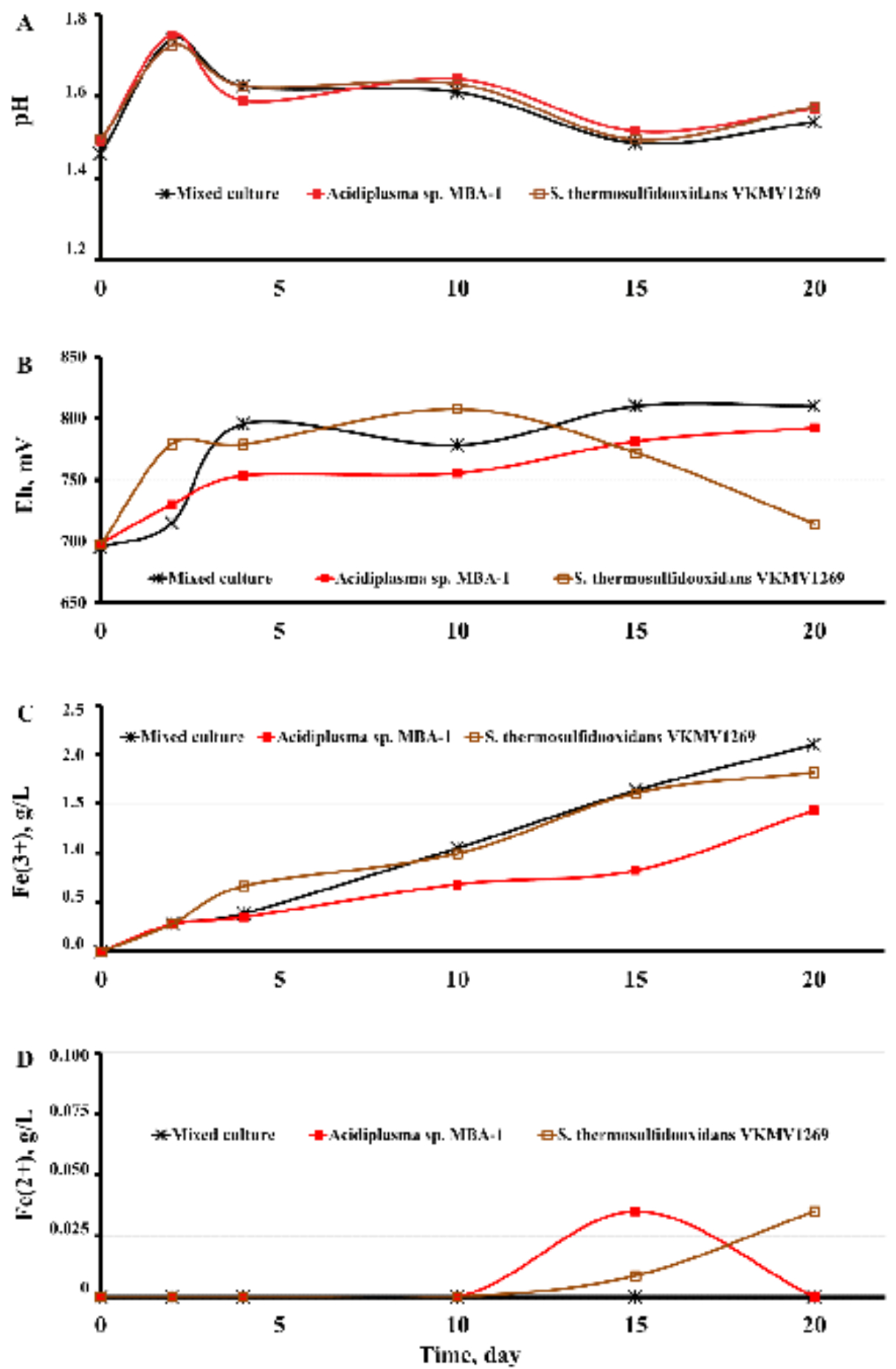

Figure 1: Changes in the liquid phase parameters during pyrite bioleaching at $45^{\circ} \mathrm{C}: \mathrm{A}-\mathrm{pH}$; $\mathrm{B}-\mathrm{Eh} ; \mathrm{C}-$ $\mathrm{Fe}^{3+}$ ion concentration (g/L); D- Fe ${ }^{2+}$ ion concentration (g/L).

the variants with initial $\mathrm{pH}$ of the medium of 1.0 corresponding to the optimum $\mathrm{pH}$ of the strain Acidiplasma sp. MBA-1.

Pyrite leaching rate was the lowest in the variant with $\mathrm{pH} 1.5$ and temperature of $60^{\circ} \mathrm{C}$ (Figure 3, bar 7), while it was also comparatively low at $\mathrm{pH} 1.5$ and temperature 

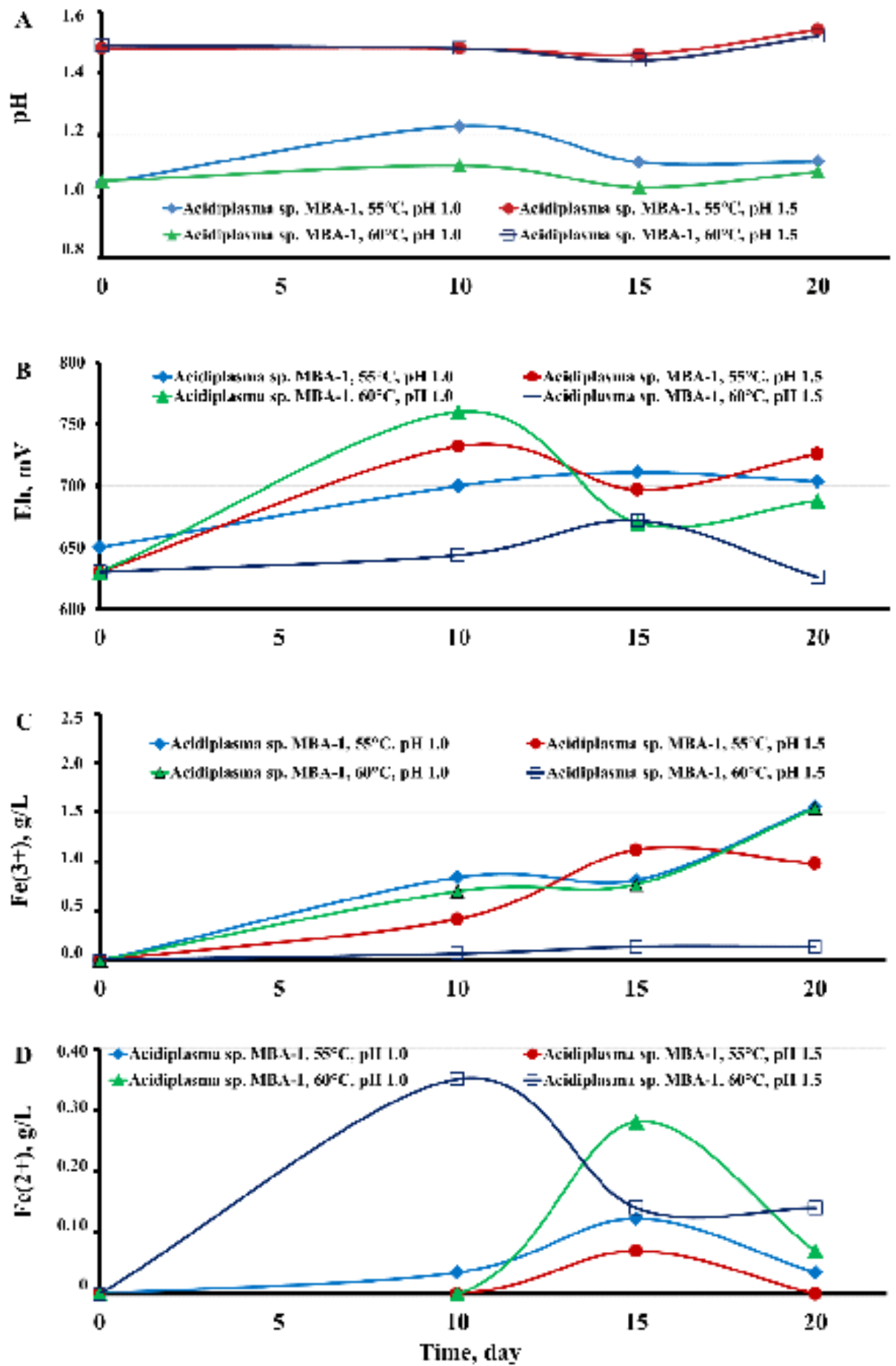

Figure 2: Changes in the liquid phase parameters during pyrite bioleaching by the strain Acidiplasma $\mathrm{sp}$ MBA-1 at 55 and $60^{\circ} \mathrm{C}: \mathrm{A}-\mathrm{pH} ; \mathrm{B}-\mathrm{Eh} ; \mathrm{C}-\mathrm{Fe}^{3+}$ ion concentration (g/L); $\mathrm{D}-\mathrm{Fe}^{2+}$ ion concentration (g/L).

of $55^{\circ} \mathrm{C}$ (Figure 3, bar 5). In the same time, leaching rates were significantly higher at 55 and $60^{\circ} \mathrm{C}$ and at $\mathrm{pH} 1.0$ (Figures 3, bars 4 and 6). In these variants, leaching rates were higher than in the experiment the strain Acidiplasma sp. MBA-1 at $45^{\circ} \mathrm{C}$ (Figure 3 , bar 3). Thus, the increase in the temperature led to the decrease in bioleaching rate at 


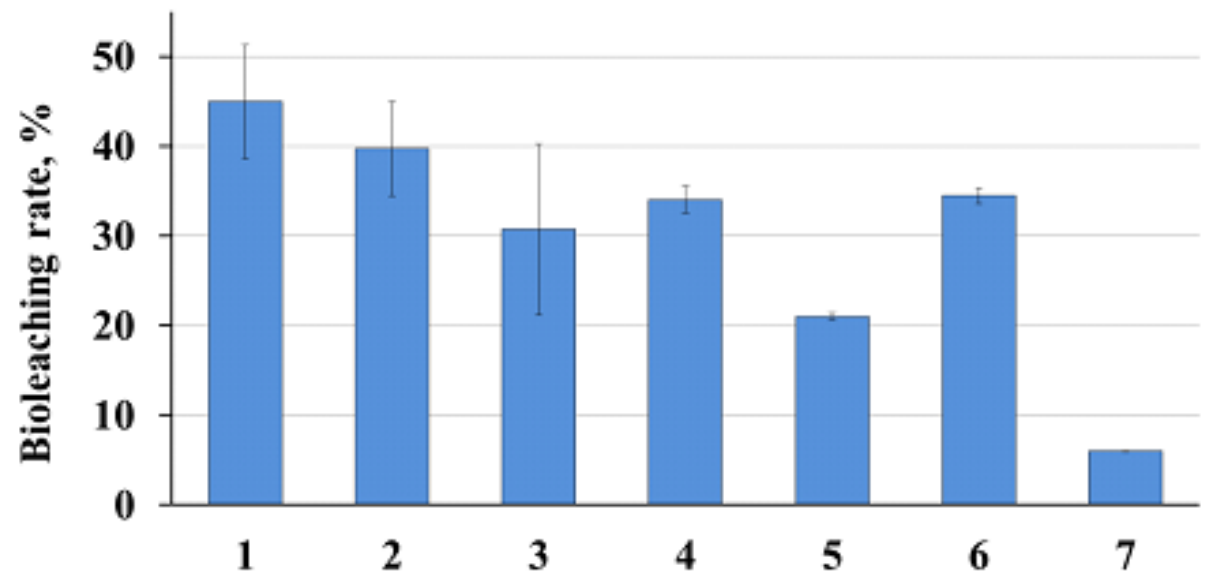

Figure 3: Rate of pyrite leaching by microorganisms under different conditions (\%): (1) mixed culture of A. caldus MBC-1, S. thermosulfidooxidans VKMV $1269^{T}$, and Acidiplasma sp. MBA-1, $45^{\circ} \mathrm{C}$, initial $\mathrm{pH} 1.5$; (2) pure culture $S$. thermosulfidooxidans $\mathrm{VKMV} 1269^{T}, 45^{\circ} \mathrm{C}$, initial $\mathrm{pH} 1.5$; (3) pure culture Acidiplasma sp. MBA-1, $45^{\circ} \mathrm{C}$, initial $\mathrm{pH} 1.5$; (4) pure culture Acidiplasma sp. MBA-1, $55^{\circ} \mathrm{C}$, initial $\mathrm{pH} 1.0$; (5) pure culture Acidiplasma sp. MBA-1, $55^{\circ} \mathrm{C}$, initial pH 1.5; (6) pure culture Acidiplasma sp. MBA-1, $60^{\circ} \mathrm{C}$, initial pH 1.0 ; (7) pure culture Acidiplasma sp. MBA-1, $60^{\circ} \mathrm{C}$, initial $\mathrm{pH} 1.5$.

$\mathrm{pH} 1.5$, while decrease in $\mathrm{pH}$ to 1.0 made it possible to reach comparatively high rate of pyrite bioleaching.

\section{Discussion}

The results of the present work demonstrated the representatives of the genus Acidiplasma provided comparatively high rate of pyrite bioleaching at high temperatures $\left(55\right.$ and $60^{\circ} \mathrm{C}$ ). In the same time, the $\mathrm{pH}$ value should be maintained at low level to maintain high oxidizing activity of the strain of the genus Acidiplasma. Despite pyrite bioleaching rates reached by the mixed culture $A$. caldus MBC-1, S. thermosulfidooxidans VKMV $1269^{T}$, and Acidiplasma sp. MBA-1 and pure culture of S. thermosulfidooxidans VKMV $1269^{T}$ were higher than those observed in the experiments with pure culture of Acidip/asma sp. MBA-1 under different conditions, application of the conditions close to the optimum of Acidiplasma sp. MBA-1 may provide some advantages. For example, biooxidation at higher temperatures may provide decrease of the costs of temperature maintaining in industrial-scale reactors. According to the results obtained, strain of the genus Acidiplasma may provide comparatively high rate of pyrite bioleaching in the case of $\mathrm{pH}$ maintaining at low level. Therefore, the results of the present work suggest that archaea of the genus Acidiplasmamay be promising microorganisms to improve bioleaching processes by means of increase in operational temperature. In the same time, this assumption should be confirmed by the performing 
of laboratory-scale trials, which may be planned based on the results obtained in the present work.

\section{Conclusions}

The results obtained in the present work may be used for planning further laboratoryscale trials to develop approaches allowing to improve biohydrometallurgical technologies by means of change operational conditions.

\section{Funding}

This work was supported by the Ministry of Science and Higher Education of the Russian Federation.

\section{References}

[1] Johnson DB.Biomining - Biotechnologies for extracting and recovering metals from ores and waste materials. Current Opinion in Biotechnology.2014;30:24-31.

[2] Mahmoud, Akrama \& Cézac, Pierre \& Hoadley, Andrew \& Contamine, François \& d'Hugues, Patrick. A review of sulfide minerals microbially assisted leaching in stirredtank reactors. International Biodeterioration \& Biodegradation.2017;119:118146.

[3] Sand, Wolfgang \& Gehrke, Tilman \& Jozsa, Peter-Georg \& Schippers, Axel. (Bio)chemistry of bacterial leaching - direct vs. indirect bioleaching.Hydrometallurgy. 2001;59:159-175.

[4] Schippers, Axel \& Jozsa, P.G. \& Sand, Wolfgang. Sulfur chemistry in bacterial leaching of pyrite. Applied and Environmental Microbiology.1996;62:3424-3431.

[5] Rawlings DE, Tributsch H, Hansford G.Reasons why 'Leptospirillum'-like species rather than Thiobacillusferrooxidans are the dominant iron-oxidizing bacteria in many commercial processes for the biooxidation of pyrite and related ores.Microbiology. 1999;145:5-13.

[6] Okibe N, Johnson DB. (2004). Biooxidation of pyrite by defined mixed cultures of moderately thermophilic acidophiles in $\mathrm{pH}$-controlled bioreactors: Significance of microbial interactions. Biotechnology and Bioengineering. 2004;87:574-583.

[7] Bulaev AG.Effect of organic carbon source on pyrite biooxidation by moderately thermophilic acidophilic microorganisms. Microbiology. 2020;89:301-308. 
[8] van Aswegen PC, van Niekerk J, Olivier W.Biomining. Rawlings DE, Johnson BD, editors. The BIOX process for the treatment of refractory gold concentrate.Berlin: Springer; 2007.

[9] Muravyov MI, Bulaev AG.A two-step process for the treatment of refractory sulphidic concentrate.Advanced Materials Research. 2013;825:246-249.

[10] Van Hille, Rob \& Wyk, Nathan \& Froneman, Tamlyn \& Harrison, Susan. Dynamic evolution of the microbial community in BIOX leaching tanks.Advanced Materials Research. 2013;825:331-334.

[11] Golyshina OV, Yakimov MM, Lünsdorf H, et al. Acidiplasmaaeolicum gen. nov., sp. nov., a euryarchaeon of the family Ferroplasmaceae isolated from a hydrothermal pool, and transfer of Ferroplasmacupricumulans to Acidiplasmacupricumulans comb. nov. International Journal of Systematic and Evolutionary Microbiology. 2009;59:2815-2824.

[12] Golovacheva RS, Karavaiko GI.A new genus of thermophilic spore-forming bacteria, Sulfobacillus.Microbiology. 1978;47:815-822.

[13] ReznikovAA, Mulikovskaya EP, SokolovlY.Metodyanalizaprirodnykhvod (Methods for Analysis of Natural Waters). Moscow: Nedra; 1970. 